\title{
RESEARCH
}

Open Access

\section{Assessment of predictors for acute asthma attack in asthmatic patients visiting an Ethiopian hospital: are the potential factors still a threat?}

Sewunet Admasu Belachew ${ }^{1 *}$, Daniel Asfaw Erku', Dawit Kumilachew Yimenu² and Begashaw Melaku Gebresillassie ${ }^{1}$

\begin{abstract}
Background: Recurrent exacerbations in patients with moderate or severe asthma are the major causes of morbidity, mortality and medical expenditure. Identifying predictors of frequent asthma attack might offer the fertile ground of asthma management. However, systematic data on asthma management is scarce in Ethiopia.

Objective: The purpose of the present study was to determine predictors of acute asthma attack in patients with asthma attending emergency department of University of Gondar Comprehensive Specialized Hospital (UOGCSH) in Gondar, northwestern Ethiopia.

Methods: An institutional-based cross-sectional self-administered survey was conducted on 108 asthmatic patients who came to the emergency department of UOGCSH following acute asthma attack. Data were collected through interviewer administered questionnaire. Logistic regression was done to see the possible association of potential factors that may lead to asthma exacerbation.
\end{abstract}

Result: About half of the respondents (51.9\%) were female and one third of patients (38.9\%) were within the age range of between 46 and 60 years. The leading potential predictor were frequent exposure to various ongoing allergen (68.5\%) followed by revelation to occupational sensitizers (67.6\%). Chronic sinusitis ( $\mathrm{AOR}=3.532,95 \% \mathrm{CL}=$ 1.116-11.178), obstructive sleep apnea ( $A O R=3.425,95 \% C L=1.255-9.356)$ and psychological disfunctioning (3.689 (1.327-10.255)) were among the significantly associated factors of acute asthma exacerbation.

Conclusions: Now days, the backbone for long-term asthma management is to prevent exacerbations. Chronic sinusitis, obstructed sleep apnea and psychosocial dysfunction were originated to be considerably linked with repeated exacerbations of asthma. Among those significantly associated predictors, obstructed sleep apnea were the most prevalent one.

Keywords: Asthma exacerbation, Ethiopia, Gondar, Hospital, Factors

\footnotetext{
* Correspondence: sewunet.admasu@gmail.com

'Department of clinical pharmacy, School of Pharmacy, University of Gondar,

P.O. Box: 196, Gondar, Ethiopia

Full list of author information is available at the end of the article
}

(c) The Author(s). 2018 Open Access This article is distributed under the terms of the Creative Commons Attribution 4.0 International License (http://creativecommons.org/licenses/by/4.0/), which permits unrestricted use, distribution, and reproduction in any medium, provided you give appropriate credit to the original author(s) and the source, provide a link to the Creative Commons license, and indicate if changes were made. The Creative Commons Public Domain Dedication waiver (http://creativecommons.org/publicdomain/zero/1.0/) applies to the data made available in this article, unless otherwise stated. 


\section{Background}

Asthma is a universal health obstacle jeopardizing beyond 300 million individuals' life of all ages, ethnic groups, and countries [1]. However, due to ecological variation, there is a considerable heterogeneity of asthma regarding gene-environment interactions, environmental acquaintances, comorbidities, age, causal disease harshness, health care availability, psychological factors, disease response to management, and disease load including asthma exacerbations and mortality as well as long-term chronic morbidity [2, 3]. Although asthma is most common in developed (westernized) countries, it is alarmingly growing in developing countries due to the amplified urbanization of communities [4, 5]. Acute asthma attacks remain a cause for regular encounter to emergency department in a hospital as a new admissions [6]. Overall, acute asthma episodes- especially hospital encounters account for uneven health expenditures compared with the treatment of stable asthma [7]. Acute exacerbation events usually give time for intervention; however in some occasions the onset of the symptoms become so rapid, better to be distinguished from periods of deprived asthma control [8-10]. However, some patients hurt from frequent asthma attack resulting in: working days and school absence, frequent emergency admission. Such asthma attacks are linked with extensive injury and constitute a significant percentage of the gross expenditures of asthma [11-13]. Emergency unit and hospitalization for asthma remain to be related to several psychosocial factors, such as inferior socioeconomic status inaccessibility of medical care and already standing mental disorders [1]. Moreover, patient individualities that drives to lethal asthma exacerbations include being female, elderly, tobacco user and non-adherence to treatment $[4,10,11]$. In addition, several modifiable and non-modifiable precipitating factors were identified in complicated asthma [14-16]. However, it is mysterious that which factors leads to the recurrence of acute asthma attack in patients with poorly controlled disease. Despite the clinical and economic prominence of acute asthma attack, merely a few researches have surveyed predictors that may lead to disease recurrence. Therefore, this study will help fill this gap and identify those predictors for unsuccessful Asthma control as well as Asthma exacerbations. This will help in the enactment of early therapeutic interventions aimed at correcting these factors which are expected to reduce morbidity and medical expenditure.

The study will also support the goverment in the effort to step down expenses for purchasing medications and by saving lost work days following Asthma attacks as well as subsequent hospital admissions. This study has also an importance for upcoming studies to be used as reference. With this, the purpose the present study is to identify predictors of acute asthma exacerbation among patients with asthma who came to emergency department of UOGCSH, Gondar town, Northwestern Ethiopia.

\section{Methods}

Study area and design

An institutional based cross sectional survey was done on adult patients who came to the emergency medicine unit of UOGCSH following asthma exacerbations. UOGCSH is the oldest referral hospital located northwestern Ethiopia. The Hospital has many wards, comprised of; Internal medicine, gynecology/obstetrics, pediatrics, surgery units and one big emergency unit. The study period was from January 1 to May 10, 2017.

\section{Sampling}

A Convenience sample of all patients with asthma who visited the hospital following acute asthma attack during the study period were included. An overall of 115 patients were invited. Patients who were capable of understanding the questionnaire were included, while patients with serious psychological/physical disorder and who rejected an offer to participate in the study were excluded. With this our study participants reduced to a final sample of 108 patients.

\section{Data collection and management}

The tool used was adopted from the previously peer-reviewed studies after brief modifications. The final format has two major parts: The first part: - demographic items (age, sex...) while the second part included items related potential predictors and adherence to asthma therapy. The data were collected by four well-trained Clinical Pharmacists through interviewer-administered questionnaires. The tool, originally written in English, was translated to local language (Amharic) then translated back to English by anther expert in order to ensure that the translated version gives the original meaning. To clarify, the diagnosis of the possible asthma exacerbating diseases such as Obstructive sleep apnea,chronic sinusitis,psychological dysfunctions and the like were made by either internship medical students, senior physicians/nurses or health officers right away at UOGCSH when they came for the management of the acute asthma attack or it was identified as the diagnosis had been already made in other else local health centers by the same professionals and in the latter case, the patient lived for a longer time with the mentioned asthma exacerbating disease but the patient failed to control it . In both occasions, as to the explanation of the respondents and the data collectors as an eye witness at UOGCSH, the diagnosis were made based on brief patient history and physical examination. The 
content validity of the tool was revised and reassured by a group of experts, including Internists physicians, health information experts, and clinical pharmacists. Pretest was employed on 20 asthmatic patients prior to the gross data collection, which was left out from the final study, and pertinent amendments were applied.

\section{Statistical analysis}

The final data collection tool were carefully checked for completeness and the filled responses first entered to and analyzed using the Statistical Package for the Social Sciences software Version 20 for Windows. The demographics of study subjects were clearly described using frequencies, percentages, tables, figures and logistic regression were used to illustrate and to explore potential associations of different variables and findings. $P$-value of 0.05 with CI of $95 \%$ was considered as a cut-off point to declare significance.

\section{Ethical consideration}

This research was ethically approved by the Ethical Review Committee of School of Pharmacy, University of Gondar with an approval number of University of Gondar (UoG)-School of Pharmacy (SoP)-120-2017. Permission from the emergency department of the hospital was also received. Written informed consent from participants was also gained prior to conducting the study. Participants' information obtained from the questionnaires was kept confidential via data coding. Participants were also informed that participation was voluntarily.

\section{Result}

\section{Patients' demographic characteristics}

For the 108 chronic patients with asthma who involved in the study; factors for asthma exacerbation and the prevalence of those potential contributing factors was assessed. About half of the study subjects (51.9\%) were female and one third of patients (38.9\%) were within the age range of between 46 and 60 years with a median age of 48 years. $65.7 \%$ of the respondents were urban residents and almost half of the total sampled patients (55.6\%) and (50.0\%) know only little about their disease and their medications, respectively. In line with this, about 23.1 and $30.6 \%$ of patients doesn't know anything about their disease and medications, respectively. The median asthma duration was 13 years with one fourth of patients $(25.9 \%)$ having duration of between 5 and 10 years. The detailed characteristics of study participants are shown in [Table 1].

In the study, many potential predictors of asthma exacerbation were identified, with this the leading one was frequent exposure to several ongoing allergen (68.5\%) followed by contact to work-related sensitizers (67.6\%) [Fig. 1].
Table 1 Socio-demographic characteristics of the study participants

\begin{tabular}{|c|c|}
\hline Variables & Frequency, N (\%) \\
\hline \multicolumn{2}{|l|}{ Gender } \\
\hline Male & $52(48.1)$ \\
\hline Female & $56(51.9)$ \\
\hline \multicolumn{2}{|l|}{ Age group } \\
\hline $18-25$ & $14(13)$ \\
\hline $26-35$ & 19 (17.6) \\
\hline $36-45$ & 19 (17.6) \\
\hline $46-60$ & $42(38.9)$ \\
\hline$>60$ & $14(13)$ \\
\hline \multicolumn{2}{|l|}{ Marital status } \\
\hline Unmarried & $27(25)$ \\
\hline Married & $69(63.9)$ \\
\hline Divorced & $2(1.9)$ \\
\hline Widowed & $10(9.3)$ \\
\hline \multicolumn{2}{|l|}{ Educational status } \\
\hline No formal education & $41(38)$ \\
\hline Secondary education & $17(15.7)$ \\
\hline Primary education & $25(23.1)$ \\
\hline Tertiary level & $25(23.1)$ \\
\hline \multicolumn{2}{|l|}{ Employment status } \\
\hline Unemployed & $58(53.7)$ \\
\hline Employed & $42(38.9)$ \\
\hline Retired & $2(1.9)$ \\
\hline Student & $6(5.6)$ \\
\hline \multicolumn{2}{|l|}{ Monthly income } \\
\hline$<500$ & $5(4.6)$ \\
\hline $500-1500$ & 75 (69.4) \\
\hline $1501-2500$ & $17(15.7)$ \\
\hline$>2500$ & $11(10.2)$ \\
\hline \multicolumn{2}{|l|}{ Area of residency } \\
\hline Rural & $37(34.3)$ \\
\hline Urban & $71(65.7)$ \\
\hline \multicolumn{2}{|l|}{ Family history of asthma } \\
\hline Yes & $27(25.0)$ \\
\hline No & $81(75.0)$ \\
\hline \multicolumn{2}{|l|}{ Duration of asthma } \\
\hline$<5$ years & $31(28.7)$ \\
\hline $6-10$ years & $28(25.9)$ \\
\hline $11-15$ years & 15 (13.9) \\
\hline 16-20 years & 15 (13.9) \\
\hline$>20$ years & 19 (17.6) \\
\hline \multicolumn{2}{|l|}{ Knowledge about asthma } \\
\hline Very good & $23(21.3)$ \\
\hline
\end{tabular}


Table 1 Socio-demographic characteristics of the study participants (Continued)

\begin{tabular}{ll}
\hline Variables & Frequency, N (\%) \\
\hline Little & $60(55.6)$ \\
No knowledge & $25(23.1)$ \\
Knowledge about asthma medications & \\
Very good & $21(19.4)$ \\
Little & $54(50.0)$ \\
No knowledge & $33(30.6)$ \\
\hline
\end{tabular}

\section{Factors associated with frequent asthma exacerbations}

Appropriate analysis model was instituted to determine predictors of frequent severe exacerbations for each of the variables in the eq.

A large number of potential factors found to be significantly associated with a minimum of one asthma exacerbation within the last two years in a bivariate analysis [Table 2]. Among factors analyzed for significant association recurrent respiratory tract infections (OR 2.953, CI 95\%), chronic sinusitis (OR 3.437, CI 95\%), obstructive sleep apnea (OR 3.394, CI 95\%), gastro-esophageal reflux disease (OR 3.474, CI 95\%), psychological dysfunction (OR 3.205, CI 95\%), ongoing allergen exposure (OR 2.778, CI 95\%), exposure to occupational sensitizers (OR 2.969 , CI 95\%) were found to be significantly associated with acute asthma attack. Other factors with potential association but not significant were; Present use of salicylates, NSAIDS, B-blockers, ACE inhibitors (OR 1.671, CI 95\%), poor adherence to medication (OR 1.412, CI $95 \%$ ), presence of pet animals at home (OR 1.123, CI 95\%), urban residency (OR 1.455, CI 95). The details of the potential factors associated with frequent asthma exacerbations as to the result of crudes odds ratio are described below at [Table 2].
After adjusting for potential confounders we tried to put the adjusted odds ratio and we come with a result that only chronic sinusitis (adjusted OR (95\% CI) 3.532(1.116-11.178)), presence of obstructive sleep apnea (adjusted OR (95\% CI) 3.426 (1.255-9.356)), presence of psychological dysfunctioning (adjusted OR (95\%) $3.689(1.327-10.255)$ ) were the mere factors found to be significantly associated with frequent asthma exacerbations. The details of the adjusted odds ratio resulted described below at [Table 3].

\section{Discussion}

This original article was aimed to pinpoint the factors associated with acute asthma exacerbations in asthmatic patients. Different scientific outputs disclosed that occurrence of asthma attack have been frequent among asthmatic patients and it is highly linked with various potential factors such as: Sinus diseases, Gastro esophageal reflux disease, and mental problem [17].

Among 108 study participants, beyond half of them have little knowledge about their disease condition and medications they are taking, (60)55.6\% and (50)54\%, respectively. This might be due to their education status since huge number of patients $41(38 \%)$ were not in formal education and majority of patients were very older (46-65 years) so that they could not be energetic to update themselves about their medical therapy and their disease status. This results concurs with the study done in Europe which claims that there were patients' lack of knowledge about asthma and its treatments which is referred as main obstacle among adult asthmatics and can estimate poor asthma control [18]. The duration of asthma per year (5-10 years) was comparable with the study done in Canada [10].

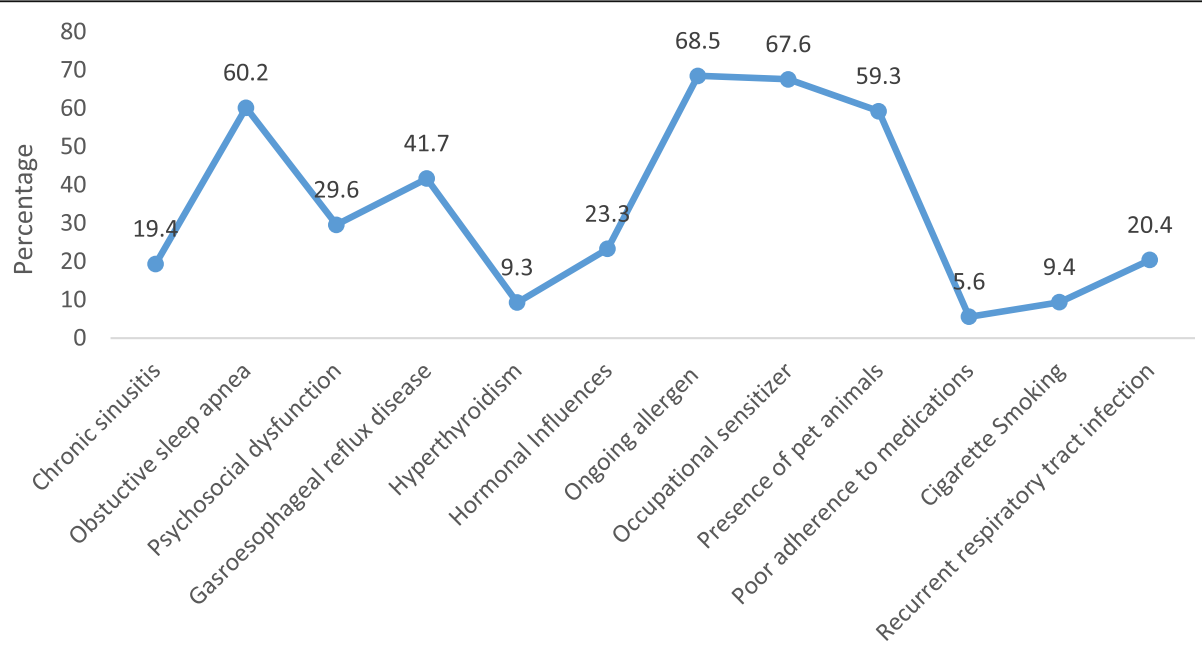

Potential risk factores

Fig. 1 Prevalence of potential risk factors of frequent asthma attack in total study population included in the analysis 
Table 2 Crude odds ratio (COR) for factors associated with frequent asthma exacerbation

\begin{tabular}{lll}
\hline Factors & COR (95\% Cl) & $P$ value \\
\hline Recurrent respiratory tract infections & $2.953(1.117-7.810)$ & 0.029 \\
Presence of chronic sinusitis & $3.437(1.256-9.405)$ & 0.016 \\
Presence/ history of obstructive sleep apnea & $3.394(1.464-7.869)$ & 0.004 \\
Presence of gastro esophageal reflux disease & $3.474(1.556-7.756)$ & 0.002 \\
Presence of psychological dysfunctioning & $3.205(1.359-7.562)$ & 0.008 \\
Ongoing allergen exposure & $2.778(1.143-6.749)$ & 0.024 \\
Exposure to occupational sensitizers & $2.969(1.224-7.202)$ & 0.016 \\
use of salicylates, NSAIDS, B-blockers, ACE inhibitors & $1.671(0.721-3.872)$ & 0.231 \\
Adherence & & 0.043 \\
$\quad$ Very good & - & 0.135 \\
Good & $3.840(0.657-2.429)$ & 0.715 \\
Poor & $1.412(0.222-8.990)$ & 0.769 \\
Presence of pet animals at home & $1.123(0.516-2.446$ \\
Residency & $1.455(0.653-3.242)$ & 0.359 \\
\hline
\end{tabular}

The study also tried to discover different potential predictors of asthma poor control and asthma attack and come up with factors like sinus disease, obstructive sleep apnea, Gastro esophageal reflux disease, psychological dysfunctions, smoking, and exposure to allergen and another number of elements. Among the potential predictors explored, the leading one was frequent exposure to several ongoing allergen(68.5\%) followed by exposure to work-related sensitizers(67.6\%). This could be justified as huge number of patients live in urban area which is believed as the key birthplaces of enormous allergens and occupational sensitizers compared to rural areas since those places are usually preferential locations for industries and other potential factories which are all widely known to emit lots of allergens and sensitizers. The possible mechanism of inhaled allergens including occupational sensitizers to cause acute asthma attack is via activating mast cells that render them to release histamines, leukotriene, Interleukin and prostaglandins that in turn lead to bronchospasm that further increase airway responsiveness as well as airway limitations.

Table 3 Adjusted odds ratio (AOR) for factors associated with frequent asthma exacerbations

\begin{tabular}{lll}
\hline Factors & AOR $(95 \% \mathrm{Cl})$ & $P$ value \\
\hline Infections & $1.534(0.470-5.013)$ & 0.479 \\
Sinus & $3.532(1.116-11.178)$ & $0.032^{*}$ \\
Sleep apnea & $3.426(1.255-9.356)$ & $0.016^{*}$ \\
GERD & $1.865(0.703-4.943$ & 0.210 \\
Psychological disfunctioning & $3.689(1.327-10.255)$ & $0.012^{*}$ \\
Allergen exposure & $1.558(0.495-4.900)$ & 0.448 \\
Occupational sensitizers & $2.044(0.677-6.176)$ & 0.205
\end{tabular}

*significantly associated at $p<0.05$
Moreover, those mediators end up with infiltrations of inflammatory cells like cytokines and other inflammatory mediators that results to airway inflammation characterized by edema, epithelial injury and impaired mucocillary functions $[19,20]$.

The study finding was incomparable with the study done in Netherland in which the front line factor identified was presence of recurrent respiratory tract infection followed by Gastro esophageal reflux disease which is quite different from our study result [17]. Having this in mind, statistical analysis was done to point out the probable is a statistical significances between those potential predictors and incidence of frequent asthma attacks. The multivariate analysis showed that Asthmatic patients having chronic sinusitis were 2.5 times more like to encounter acute asthma attack compared to those who have not yet faced this co-morbid $(\mathrm{AOR}=3.532$, 95\% $\mathrm{CL}=1.116-11.178$ ). This might be due to the fact that large number of the study subjects live in urban area and in this place there are many chemicals, gases and the like that will worsen the sinusitis status then end up with acute attack. Both seasonal and viral chronic sinusitis are among the most common triggers of acute severe exacerbations and may invade epithelial cells of the lower as well as the upper airways and there is an increase in airway inflammation with increased numbers of eosinophil and neutrophils along with nasal congestion as well as airway tract edema in addition to increment in airway hyper-responsiveness $[19,20]$. The existence of obstructive sleep apnea(OSA) also was 2.4 times more like to run in to acute asthma attack compared to those who had not $(\mathrm{AOR}=3.425,95 \% \mathrm{CL}=$ 1.255-9.356). The possible mechanisms by which OSA lead to the worsening of asthma control in patients with 
concomitant OSA include Neuro-mechanical reflex bronchoconstriction because of increase vagal tone while sleeping, increased prevalence of gastro-esophageal reflux with OSA, increased inflammation and the indirect effect on dyspnea of OSA-induced cardiac dysfunction [21]. In addition to those, owing psychological dysfunction was 2.6times more like to run in to acute asthma attack compared to those who had not $(\mathrm{AOR}=$ $3.689,95 \% \mathrm{CL}=1.327-10.255)$. Basically, in Psychological dysfunctioning, the probable mechanism to acute worsening of asthma have been related with stress. There is no doubt that psychological factors can induce bronchoconstriction through cholinergic reflex pathways [19]. Those findings were comparable with the study done in Netherland, Leiden University (AOR $=3.7,95 \mathrm{CL}=1.2-$ $11 . .9, \mathrm{AOR}=3.4,95 \% \mathrm{CL}=1.2-10.4, \mathrm{AOR}=10.8,95 \% \mathrm{CL}$ $=1.1-108.4$, respectively) [17].

Apart from those factors, the multivariate analysis showed that other potential predictors were not significantly associated with asthma exacerbation but to the contrary the study conducted in Netherland claimed that factors like recurrent respiratory tract infections $(\mathrm{AOR}=$ 6.9,95\% CL $=1.9-24.7$ ), Gastro-esophageal reflux (AOR $=4.9,95 \% \mathrm{CL}=1.4-17.8$ ) are significantly associated with acute asthma exacerbations [16]. In GERD, acid reflux might trigger reflex bronchoconstriction bur rarely cause asthma symptoms [19]. Unlike this study, one study revealed that pathological gastro-esophageal reflux is considered a potential trigger of asthma, even in the non-existence of esophageal symptoms [22]. To strengthen the point rose regarding chronic sinusitis which had been suggested to take part in poor controlled asthma and asthma exacerbation.

Appropriate treatment of sinusitis in asthmatic patients have been shown to result in both improved Sino nasal and asthmatic symptoms with very fewer physician visits and decreased need for medication in several patients [23, 24]. Comparably to our study, lots of psychosocial factors have been drivers of severe frequent asthma attacks [17, 22]. A study stated that, if psychological disturbances are recognized and properly managed, frequency of acute asthma attack and the detrimental consequences might be significantly abridged [23].

In line with the above mentioned predicators, there are also other factors that had been identified to be associated with acute asthma attack although were proved to be not significant. Those were medication used concomitantly such as salicylates, ACE inhibitors, B-blockers and the like. To mention the probable mechanisms, Angiotensin-converting enzyme inhibitors are theoretically detrimental as they inhibit breakdown of kinins, which are broncho-constrictors while Aspirin augments the leukotriene path that lead bronco constrictions. In addition, although the mechanisms of beta-blockers are not clear but are likely mediated through increased cholinergic bronchoconstriction [19].

As a limitation, the present study was done in a single town and cannot be fully generalized to other places in Ethiopia although the result can be used as input for upcoming nationwide investigations. In addition, all measures used were based on self-reporting, this might end up with socially desirable responses.

\section{Conclusion}

Now days, the backbone for chronic asthma management is to prevent its exacerbations. This calls for improved understanding of predictors that contribute to the incidence of severe disease exacerbations. The present study, looking for asthmatic patients according to a systematic protocol, provides a clinical profile of the patients with acute asthma attack. In particular, chronic sinusitis, obstructive sleep apnea and psychosocial dysfunction were found to be significantly associated with frequent acute asthma attack. Among those significantly associated predictors, Obstructive sleep apnea were the top one.

\section{Implications}

It can be anticipated that rigorous treatment of these comorbid factors will end up in less asthma exacerbations with better disease control, which will prominently enhance the quality of life of patients with chronic asthma. Taking into consideration the heightened importance of clearly identifying the reasons for repeated hospital admissions following acute asthma exacerbations so as to prevent the number of chronic asthmatics who encounter acute exacerbations, different stakeholders working in the health sector particularly in asthma control should provide a customized health promotion intervention and awareness creation to chronic asthmatic patients living in urban and rural areas. Finally, taking the result of this study as input, we do recommend researchers to work on a multi-centered study with a huge number of sample population for better generalization.

\author{
Acknowledgements \\ The author acknowledges the support of the school of Pharmacy, University \\ of Gondar, in facilitating the data collection process. \\ Funding \\ The author(s) received no specific funding for this work. \\ Availability of data and materials \\ All relevant data are on the hand of the principal investigator. \\ Authors' contributions \\ All authors stated that they contributed equally to the work and mentioned \\ that they had complete access to the study data that support that \\ publication.
}




\section{Ethics approval and consent to participate}

This study was approved by the ethical review committee of School of Pharmacy, University of Gondar with an approval number of UoG-SoP-120/ 2017. Written informed consent from the participants was also obtained before conducting this study. Participants' information gained was kept confidential.

\section{Consent for publication}

Not applicable.

\section{Competing interests}

The authors have declared that no competing interests exist.

\section{Publisher's Note}

Springer Nature remains neutral with regard to jurisdictional claims in published maps and institutional affiliations.

\section{Author details}

'Department of clinical pharmacy, School of Pharmacy, University of Gondar, P.O. Box: 196, Gondar, Ethiopia. ${ }^{2}$ Department of pharmaceutics and social pharmacy, School of Pharmacy, College of medicine and health sciences, University of Gondar, Gondar, Ethiopia.

Received: 3 January 2018 Accepted: 6 July 2018

Published online: 16 July 2018

\section{References}

1. J B. K K. Global surveillance, prevention and control of chronic respiratory diseases: a comprehensive approach. Global alliance against chronic respiratory diseases. Geneva: World Health Organization; 2007.

2. SE W. Asthma: defining of the persistent adult phenotypes. Lancet. 2006; 368:804-13.

3. JM FitzGerald, PG Gibson.Asthma exacerbations.Downloaded from https:// thorax.bmj.com/content/thoraxjnl/61/11/992.full.pdf/ on November 15, 2015 - published by group.bmj.com.Thorax 2006;61:992-999. doi: https://doi.org/ 10.1136/thx.2005.045195.

4. Asher Ml, Montefort S, Bjorksten B, Lai CK, Strachan DP, Weiland SK, et al. Worldwide time trends in the prevalence of symptoms of asthma, allergic rhinoconjunctivitis, and eczema in childhood: ISAAC phases one and three repeat multicountry cross-sectional surveys. Lancet. 2006;368(9537):733-43.

5. Glf A. Global strategy for asthma management and prevention. NIH publication no. 02-3659. National Institutes of Health. National Heart Respiratory. Journal. 1998;12(5):1209-18.

6. Adams R, Ruffi R, Wakefield M, Campbell D, Smith B. Asthma prevalence, morbidity and management practices in South Australia, 1992-1995. Aust NZ J Med. 1997;27(6):672-9.

7. Awadh N, Grunfeld A, FitzGerald JM. Health care costs associated with acute asthma. A prospective economic analysis. Can Respir J. 1999;6:521-5.

8. Chan-Yeung M, Chang JH, Manfreda J, et al. Changes in peak flow, symptom score, and use of medications during acute exacerbations of asthma. Am J RespirCrit Care Med. 1996;154:889-93.

9. Reddell $H$, Ware $S$, Marks $G$, et al. Differences between asthma exacerbations and poor asthma control. Lancet 199. 353:364-9.

10. Turner MO, Noertjojo K, Vedal S, et al. Risk factors for near-fatal asthma. A case-control study in hospitalized patients with asthma. Am J Respir Crit Care Med. 1998 Jun;157(6 Pt 1):1804-9.

11. Braman SS. The global burden of asthma. Chest. 2006;130(1 Suppl):4S-12S. https://doi.org/10.1378/chest.130.1_suppl.4S.

12. Grant EN, Alp H, Weiss KB. The challenge of inner-city asthma. CurrOpinPulm Med. 1999;5:27-34.

13. Weiss KB, Sullivan SD. The economic costs of asthma: a review and conceptual model. PharmacoEconomics. 1993;4(1):14-30.

14. Heaney LG, Conway E, Kelly C, et al. Predictors of therapy resistant asthma: outcome of a 4systematic evaluation protocol. Thorax. 2003;58:561-6.

15. Robinson DS, Campbell DA, Durham SR, Pfeffer J, Barnes PJ, Chung KF. Systematic asessment of difficult to- treat asthma. EurRespir J. 2003;22: 478-83.

16. Barnes PJ, Woolcock AJ. Difficult asthma. EurRespir J. 1998;12:1209-18.

17. ten Brinke A, Sterk PJ, Masclee AAM. Etal. Risk factors of frequent exacerbations in difficult-to-treat asthma. EurRespir J. 2005;26:812-8.
18. Soriano JB, Rabe KF, Vermeire PA. Predictors of poor asthma control in European adults. J Asthma. 2003;40(7):803-13.

19. Longo Dan L, Kasper Dennis L, Larry Jameson J. Et al. Harrison's principle of internal medicine. 18th ed. USA: The McGraw-Hill Companies; 2012. Chapter 344

20. DiPiro JT, Talbert RL, Yee GC, Matzke GR, Wells BG, Posey LM. Pharmacotherapy: a pathophysiologic approach. 9th ed. New York, USA: McGraw-hill Education; 2014.

21. Alkhalil M, Schulman E, Getsy J. Obstructive sleep apnea syndrome and asthma: what are the links? JClin Sleep Med. 2009;5(1):71-8.

22. Harding SM, Guzzo MR, Richter JE. The prevalence of gastroesophageal reflux in asthma patients without reflux symptoms. Am J Respir Crit Care Med. 2000;162:34-9.

23. Adams RJ, Fuhlbrigge AL, Finkelstein JA, Weiss ST. Intranasal steroids and the risk of emergency department visits for asthma. J Allergy Clin Immunol. 2002;109:636-42.

24. Senior BA, Kennedy DW. Management of sinusitis in the asthmatic patient. Ann Allergy Asthma Immunol. 1996;77:6-15.

\section{Ready to submit your research? Choose BMC and benefit from:}

- fast, convenient online submission

- thorough peer review by experienced researchers in your field

- rapid publication on acceptance

- support for research data, including large and complex data types

- gold Open Access which fosters wider collaboration and increased citations

- maximum visibility for your research: over $100 \mathrm{M}$ website views per year

At BMC, research is always in progress.

Learn more biomedcentral.com/submissions 